\title{
DA COLONIZAÇÃO À AGÊNCIA DOS ATORES: A IMPLEMENTAÇÃO DE POLÍTICAS PÚBLICAS POR ORGANIZAÇÕES CIVIS ${ }^{1}$
}

\author{
Cláudia Tirelli \\ Universidade de Santa Cruz do Sul - UNISC - Brasil
}

\section{Resumo}

O artigo discute as diferentes apropriações de uma política pública - Programa Rede Parceria Social - pelas organizações civis que atuam na área da Assistência Social no Rio Grande do Sul, através da realização de dois estudos de caso nos anos de 2011 e 2012 . A partir de uma perspectiva teórica assentada na sociologia relacional e no institucionalismo histórico, analisase de que forma a trajetória institucional dos atores sociais, a qual os levou a ocupar no presente determinadas posições (relacionais) no campo da Assistência, condiciona a sua forma de interpretar se apropriar de oportunidades políticas como a representada pelo Programa Rede Parceria Social. Nesse sentido, coloca-se sob suspeição as teses proferidas pelas Ciências Sociais brasileiras que apontam para processos generalizados de "colonização" das organizações da sociedade civil pelo mercado ou da sua "hegemonização" por um projeto político neoliberal. Neste artigo parte-se da premissa de que a forma através da qual as organizações irão se relacionar com as oportunidades políticas, em determinada conjuntura, é algo a ser verificado por intermédio de investigações empíricas e, portanto, não pode ser respondido através de inferências causais que respondem a priori sobre a intencionalidade dos agentes e sobre os resultados de suas ações.

Palavras-chave: Rede Parceria Social. Assistência Social. Sociologia Relacional. Institucionalismo Histórico.

\section{Introdução}

Desde os anos de 1990, no Brasil, os policy makers começaram a prever a participação da sociedade civil nas políticas públicas, seja na sua fase de formulação e planejamento, seja na sua implementação, controle social e avaliação. No entanto, esses processos participativos passaram a ser concretizados e interpretados de forma muito distinta. Este artigo busca discutir a implementação de uma política pública na Área da Assistência, desenvolvida no Estado do RS, a partir de meados dos anos 2000, o Programa Rede Parceria Social (PRPS), o qual prevê o estabelecimento de parcerias público-privadas e a adoção de ferramentas de

\footnotetext{
${ }^{1}$ Este artigo constitui uma versão ampliada e modificada de um trabalho apresentado na X Bienal del coloquio de transformaciones territoriales, ocorrida em Córdoba/Argentina, entre os dias 5 e 7 de novembro de 2014.
} 
gestão por parte das organizações civis que implementam as ações do programa, com vistas a alcançar uma maior eficácia das políticas assistenciais no RS. Busca-se analisar como se deu a apropriação dessa política pública pelos distintos atores civis envolvidos na sua execução e implementação, problematizando as teses produzidas no âmbito das Ciências Sociais brasileiras que apontam para processos generalizados de "colonização" das organizações da sociedade civil pelo mercado ou da sua "hegemonização" por um projeto político neoliberal. Nesse sentido, procura-se construir um aporte teórico que possibilite resgatar a agência dos atores envolvidos na implementação das políticas, mesmo considerando que seja uma agência relativa, posto que se encontra limitada à um campo de possibilidades.

A pesquisa foi realizada a partir de dois estudos de caso, desenvolvidos entre $2011 \mathrm{e}$ 2012, em organizações sociais que integraram o Programa Rede Parceria Social/RS (PRPS) nas suas três primeiras edições (2008-2010): O Círculo Operário Leopoldense (COL) e a Themis - Assessoria Jurídica e Estudos de Gênero. Estas duas organizações foram selecionadas por apresentarem ecologias organizacionais ${ }^{2}$ e trajetórias institucionais distintas, desde o seu período fundacional até o presente. O COL foi criado em 1935, no âmbito da expansão do Movimento Circulista promovido pela Igreja Católica no Brasil e, desde a sua origem, esteve voltado a dar assistência aos pobres através de grandes instituições (orfanatos e escolas). Já a Themis foi criada em 1993, quando surgiram inúmeras ONGs no Brasil direcionadas à defesa de direitos de determinados grupos socais. Desde o princípio, esta organização se pautou pela defesa dos direitos humanos das mulheres, principalmente no que se refere ao acesso à justiça.

A opção por essas duas organizações para a realização de estudos de caso múltiplos se deu em função delas permitirem levantar mais evidências que contradigam os argumentos que a literatura brasileira tem utilizado para explicar os processos de mudança nas organizações sociais. Conforme Yin (2001), a utilização de estudos de casos múltiplos deve seguir uma lógica de replicação e não de amostragem. Martins (2008 p. 13, grifo nosso), irá afirmar que "Cada caso deve ser selecionado de modo a prever resultados semelhantes ou, inversamente, produzir resultados contrastantes por razões previsíveis." Esta última alternativa é que nos motivou a desenvolver os estudos de caso, pois permite falsear os argumentos predominantes sobre o tema. Os estudos de caso foram desenvolvidos por meio

\footnotetext{
${ }^{2}$ As ecologias organizacionais, segundo Lavalle (2011), referem-se aos diferentes formatos organizacionais existentes no tecido associativo.
} 
de observações diretas em reuniões e eventos das organizações, análise documental e entrevistas semiestruturadas com alguns de seus integrantes. ${ }^{3}$

$\mathrm{O}$ artigo encontra-se estruturado em quatro seções: na primeira seção, descreve-se o processo de reconfiguração da área da Assistência Social ocorrido no Brasil na década de 1990; na segunda seção, expõe-se os objetivos e princípios que noretearam a construção do Programa Rede Parceria Social; na terceira, problematiza-se a literatura que apresenta as teses da colonização ou da hegemonização da sociedade civil e se apresenta as referências teóricas que sustentam este artigo; e, por fim, na quarta seção, expõe-se os principais resultados dos estudos de caso e as conclusões do trabalho.

\section{0 processo de reconfiguração da Área da assistência no Brasil na década de 1990}

Na década de 1990, no Brasil, ocorreu um amplo processo de reconfiguração da área da Assistência Social, resultante de uma série de mudanças macrossociais (TIRELLI, 2013). Entre essas mudanças, destacam-se as seguintes:

1.1 A emergência de uma nova legislação para o setor

Nesse período foram aprovadas diversas leis que atingiram os atores da área da assistência, como, por exemplo, o Estatuto da Criança e do Adolescente (ECA), aprovado em 1990, e a Lei Orgânica da Assistência Social (LOAS), em 1993. Também foram criadas as leis que constituem o chamado "Marco Legal do Terceiro Setor", com destaque para a Lei das Organizações da Sociedade Civil de Interesse Público (OSCIPs), de 1999, e a Lei das Organizações Sociais (OS), de 1998, ambas relacionadas aos procedimentos de “publicização" previstos no Programa de Reforma do Estado de 1995, no $1^{\circ}$ Governo Fernando Henrique Cardoso (FHC). Essas novas legislações vão afetar as organizações sociais que atuam no campo da assistência, pois, por um lado, vão disciplinar a condução do trabalho social e a distribuição dos seus recursos, exigindo um maior planejamento e profissionalização das atividades desenvolvidas e; por outro, vão abrir novos espaços para a contratualização de organizações da sociedade civil para a execução de programas e projetos vinculados às políticas públicas setoriais ou, em alguns casos, para o desenvolvimento de projetos desenvolvidos paralelamente a essas políticas.

\footnotetext{
${ }^{3} \mathrm{O}$ anonimato dos entrevistados nesta investigação foi garantido, evitando qualquer tipo de constrangimento para os participantes da pesquisa.
} 
1.2 A ampliação dos espaços de participação institucional para as organizações da sociedade civil

A partir da redemocratização do país e da aprovação da Constituição de 1988, vários espaços foram abertos à participação das organizações da sociedade civil (Orçamentos Participativos, conselhos gestores de políticas, conselhos de direitos, fóruns, conferências públicas, etc.). Esta participação passou a exigir uma maior especialização e profissionalização dos quadros das organizações sociais, sobretudo daquelas que não estavam habituadas a trabalhar com base em procedimentos de planejamento e de gestão. (DAGNINO, 2002)

1.3 A entrada de novos atores associativos no campo da assistência

Nessa conjuntura observa-se, também, a entrada de novos atores associativos no campo da assistência (ONGs, fundações e institutos empresariais, empresas, organismos de cooperação internacional), os quais irão se somar às organizações tradicionais vinculadas a esse espaço, ou seja, às organizações/entidades caritativas e às instituições assistenciais do Estado.

Os anos 1990 vão representar um período de expressivo crescimento do número de organizações sociais no Brasil, sobretudo das identificadas como Organizações Não Governamentais (ONGs) voltadas à defesa de direitos. ${ }^{4}$ No decorrer dos anos 1990 vão ser criadas inúmeras organizações voltadas à defesa de direitos de públicos e causas específicas, em função das oportunidades políticas abertas pelo Estado brasileiro ${ }^{5}$ e pelos organismos de cooperação multilaterais e bilaterais, que elegem as ONGs como parceiras ideais para o desenvolvimento de seus projetos sociais no Brasil. Esses organismos desempenharam um papel crucial para alavancar e legitimar um novo modelo de trabalho social no Brasil e em outros países periféricos. Segundo Sorj,

O consenso em torno da sociedade civil como ator capaz de produzir um curto circuito nas instituições estatais (consideradas como fonte de corrupção e ineficiência) fazia dela a ideia adequada para apropriação pelas instituições internacionais [...]. (SORJ, 2005, p. 10).

\footnotetext{
${ }^{4}$ A pesquisa FASFIL 2010 realizada pelo IBGE, IPEA, GIFE e ABONG (2012) revela um expressivo crescimento no número de organizações de defesa de direitos durante a década de 90 , quando representavam $31 \%$ do total de organizações sem fins lucrativos existentes no Brasil e, de forma ainda mais acentuada, durante a primeira década do Séc. XXI, quando passam a representar $40,8 \%$ do total.
} 
De acordo com Paula e Rodhen (1998), os anos 1990 também apresentaram uma mudança significativa nas ações de responsabilidade social promovidas por empresários no Brasil, pois essas deixaram de se constituir enquanto iniciativas isoladas de alguns empresários benfeitores para tornarem-se estratégias das empresas ${ }^{6}$ previstas no seu planejamento orçamentário e na sua estrutura organizacional. Neste sentido, em 1995 é criado formalmente o GIFE (Grupo de Institutos, Fundações e Empresas), o qual, conforme Jaime (2005, p. 960), “[...] vem demarcando sua posição no campo da ação social a partir de conceitos como terceiro setor, filantropia empresarial e investimento social privado". O GIFE busca diferenciar suas ações sociais daquelas promovidas por entidades filantrópicas voltadas à atividade assistencial, demarcando a necessidade de se fazer uso de ferramentas de gestão, com planejamento, monitoramento e avaliação dos projetos sociais (ALMEIDA, 2006; JAIME, 2005). Em 1998 é formado o Instituto Ethos de Responsabilidade Social, uma organização empresarial que defende a gestão socialmente responsável. Segundo Muller (2006), essas organizações empresariais têm se mostrado hábeis na realização de eventos, premiações, seminários, cursos formativos, enfim, numa série de atividades direcionadas à divulgação e legitimação da sua forma de gerir o trabalho social.

\subsection{Alterações nas formas de sustentabilidade financeira das organizações}

Muitas organizações da sociedade civil brasileira recebiam recursos financeiros de organismos e agências de cooperação internacional, bem como de ONGs internacionais, sobretudo as de origem europeia e canadense. Conforme a ABONG (2010), grande parte das doações internacionais da década de 1990 visava reforçar as organizações civis brasileiras, ainda frágeis dada a longa duração do Regime Militar no país.

No entanto, a partir de meados dos anos de 1990, esses recursos passam a ser redirecionados para o continente africano e, aqueles que foram mantidos em solo brasileiro, deslocaram-se para organizações dos estados da Região Nordeste .(ABONG, 2010)

\footnotetext{
${ }^{6}$ Em artigo sobre o Prêmio ECO (Prêmio Empresa Comunidade), promovido pela AMCHAM, Paula e Rodhen (1998) explicitam essa mudança nas ações de responsabilidade social corporativa.
} 
A nosso ver, esse conjunto de mudanças vão conformar uma conjuntura crítica $^{7}$ na década de 1990, abrindo novas oportunidades e constrangimentos para as organizações sociais do campo da assistência, ao mesmo tempo em que são problematizadas as formas tradicionais de organização e atuação daqueles atores (TIRELLI, 2013).

A partir dessa conjuntura, pode-se identificar no campo da Assistência a conformação de duas perspectivas que avaliam diferentemente o papel do Estado e das organizações civis na área assistencial, apontando para caminhos opostos. Os formuladores do Programa Rede Parceria Social, objeto desta pesquisa, se filiam a uma dessas vertentes, que aposta na contratualização, pelo Estado, das organizações da sociedade civil para a provisão dos serviços de assistência. Caberia ao Estado, nessa perspectiva, fazer a gestão do processo, por meio da contratação dos serviços, do repasse de recursos e do controle dos resultados. Os atores sociais que compartilham dessa posição vão criticar a prestação de serviços realizada pelas instituições da malha estatal, salientando a sua ineficiência e o seu alto custo, na medida em que grande parte dos recursos seria utilizada para a reprodução da burocracia estatal e não pelos próprios beneficiários das ações assistenciais.

Esse modelo tem sido amplamente criticado pela literatura produzida nas Ciências Sociais, que ora o acusa de ser funcional ao projeto neoliberal de desresponsabilização do Estado com relação à garantia dos direitos sociais (MONTAÑO, 2002; COUTINHO, 2011; PAOLI, 2002) ora de colonizar as organizações da sociedade civil pelas razões instrumentais provenientes das esferas do mercado e do Estado (MÜLLER, 2006). Essas críticas também são reproduzidas em boa parcela das publicações recentes da área do Serviço Social (MESTRINER, 2001; YASBEK, 2009; SOARES, 2012), nas quais se denuncia o processo corrente de refilantropização da assistência social através de programas e projetos estruturados a partir do estabelecimento de parcerias do Estado com as organizações do Terceiro Setor e com os atores empresariais para a execução dos projetos sociais.

Esses dois caminhos paralelos têm acompanhado as discussões na área da Assistência, desde os anos de 1990, envolvendo diferentes segmentos de atores estatais e societários em torno de cada um deles. ${ }^{8}$ Dentro desse contexto, o PRPS vai estabelecer uma

\footnotetext{
${ }^{7} \mathrm{O}$ conceito de conjuntura crítica, desenvolvido dentro do Institucionalismo Histórico, permite explicar como, em determinadas conjunturas, se afrouxam os condicionantes estruturais que levava os atores a reproduzirem certos padrões institucionais e se reforça o seu poder de agência, permitindo que os atores tomem decisões antes improváveis. Para mais informações a esse respeito, consultar Capoccia e Kelemen (2007).

${ }^{8}$ Dowbor (2009) demonstra em seu trabalho como foram se articulando, desde o final dos anos 1980 e ao longo dos anos 1990, esses diferentes projetos na área da assistência, reunindo atores estatais e societários distintos em torno deles. As organizações de representação profissional dos assistentes sociais, assim como parte significativa desses profissionais atuantes dentro do Estado e nas universidades públicas e privadas, engajaram-se fortemente
} 
linha de continuidade com o modelo de trabalho social instituído, em meados dos anos 1990, pelo Programa Comunidade Solidária (PCS) no Primeiro Governo Fernando Henrique Cardoso (PSDB), o qual, por sua vez, correspondia às prescrições feitas no Programa de Reforma do Estado para a área social.

\section{O Programa Rede Parceria Social}

O Programa Rede Parceria Social foi criado em 2007, no Estado do Rio Grande do Sul (RS), durante a gestão da governadora Yeda Crusius. A concepção do programa, conforme relatado pelo então Secretário da Justiça e do Desenvolvimento Social naquela gestão governamental, Fernando Schüller, baseou-se na Lei Federal de Incentivo à Cultura Lei Rouanet, pois buscava captar recursos de empresas privadas, através da renúncia fiscal, e realocá-los em projetos sociais na Área da Assistência, os quais seriam executados por organizações/entidades assistenciais.

Todos os pressupostos apontados pela literatura como característicos de um modelo gerencial se encontram contemplados nesse Programa, a saber: o incentivo as "parcerias público-privadas", a ideia de "sinergia", o desenvolvimento do "capital social" e do "capital humano", a busca pela "eficácia e eficiência" nos projetos sociais, a valorização dos procedimentos de gestão, entre outros aspectos. Segundo a Revista Rede Parcerias Sociais (2009), o PRPS pretende passar

\footnotetext{
De uma lógica da assistência, com um Terceiro Setor dependente dos recursos governamentais e desarticulado, a Rede Parceria Social objetiva promover uma lógica de desenvolvimento, com autonomia e interatividade de todos os atores, dando início a um novo momento na trajetória do setor social no Rio Grande do Sul: um momento de modernidade, qualificação, inserção no ambiente internacional. Um momento de planejamento sólido e conquista de objetivos conjuntos (Revista Rede Parcerias Sociais, 2009, p. 8).
}

Embora o PRPS adote uma determinada perspectiva dentro do campo da Assistência, Social, ele oferece um cenário da diversidade existente no tecido associativo no RS e permite inferir a respeito de como as distintas organizações civis vêm atuando frente às oportunidades e ameaças políticas no contexto analisado. O espectro associativo abrangido pelo programa é extremamente variado, tanto no que se refere ao tamanho das organizações, como em relação

na construção e aprovação da LOAS e, posteriormente, do SUAS. Paralelamente a este processo, constituiu-se o Programa Comunidade Solidária, baseado no estabelecimento de parcerias público-privadas e da articulação de atores da sociedade civil, de segmentos empresariais e do Estado para desenvolverem projetos sociais focalizados em comunidades em condições de extrema pobreza. O Programa Comunidade Solidária não se encontrava inserido nas instituições previstas para a implementação, nos vários níveis do Estado, da Política da Assistência. 
aos seus objetivos, formas de sustentabilidade, anos de atuação, vínculos institucionais, filiações políticas e religiosas, entre outros aspectos. ${ }^{9}$ Esta diversidade permite analisar como organizações com trajetórias institucionais e com diferentes "ecologias organizacionais"- vêm interpretando e (re) agindo frente a uma série de mudanças no campo da assistência observadas a partir dos anos 1990.

\section{A contribuição da sociologia relacional e do institucionalismo histórico para a compreensão das ações coletivas e do associativismo}

No transcorrer da década de 2000, foram desenvolvidos vários trabalhos dentro do campo de estudos sobre ações coletivas e associativismo no Brasil (LAVALLE, 2011; HOUTZAGER, LAVALLE e ACHARYA, 2004; SILVA, 2006, ABERS e BÜLLOW, 2011, MARQUES, 1999, DOWBOR, 2009) que problematizaram as análises baseadas em pressupostos essencialistas e homogeneizantes em relação à sociedade civil. Esses trabalhos procuraram construir referenciais de análise que permitissem compreender a diversidade na constituição e no funcionamento do tecido associativo brasileiro, sem tomar a sociedade civil como possuidora de um estatuto político definido a priori, mas percebendo-a como um campo multifacetado de relações envolvendo atores e intencionalidades variadas, os quais apresentam distintas adaptações e apropriações das oportunidades e obstáculos políticos que se colocam em cada contexto específico. Estas abordagens não se filiam a uma perspectiva teórica em particular, embora apresentem certos elementos em comum, tanto nas suas críticas em relação à literatura produzida nos anos 1980 e 1990 acerca dos movimentos sociais e da sociedade civil, como na sua busca por novas perspectivas teóricas e metodológicas voltadas a compreensão dos atores associativos e da sua participação na esfera pública.

Um dos aspectos que parece unificar essas análises é o fato delas se pautarem por uma perspectiva relacional, na qual se busca construir explicações acerca das ações dos atores associativos a partir das relações que estes estabeleceram e estabelecem no presente com os demais atores associativos, com ONGs, agências e organismos internacionais e com as instituições políticas nacionais. Estas abordagens têm enfatizado a importância da realização de investigações empíricas para a compreensão dos atores associativos, seus atributos e suas

\footnotetext{
9 Dentre as organizações que participam do Programa Rede Parceria Social encontram-se associações comunitárias e de moradores, mitras diocesanas, APAES, creches e escolas infantis, asilos, abrigos, fundações e institutos empresariais, associações de assistência a crianças e adolescentes, clubes de mães, associações de pais e mestres, organizações de defesa de direitos de grupos sociais específicos (mulheres, negros, indígenas), casas de passagem, organizações de defesa do meio-ambiente, associações de apoio a pessoas com determinadas enfermidades, cooperativas de geração de renda, etc..
} 
formas de participação, ao invés de partir de afirmações normativas acerca da constituição dos atores e de suas propensões para a ação. Nesse sentido, Marques $(1999$, p. 47) vai dizer que, “[...] as instituições, a estrutura social e as características de indivíduos e grupos são cristalizações dos movimentos, trocas e 'encontros' nas múltiplas e intercambiantes redes de relações ligadas e superpostas."

Esses trabalhos visam construir perspectivas teóricas que, por um lado, rompam com visões deterministas e pré-concebidas em relação à constituição dos atores associativos e às razões que os movem e condicionam as suas ações e, por outro, que possibilitem analisá-los com base nas posições que ocupam nas teias de relações de interdependência que limitam suas opções e escolhas.

Buscando explicitar a forma de análise adotada pela sociologia relacional, Marques vai afirmar que ela

[...] parte do estudo de uma série de situações concretas para investigar a interação entre, de um lado, as estruturas presentes, constituídas pelos padrões de interações e trocas e as posições particulares dos vários atores, e, de outro, as ações, estratégias, constrangimentos, identidades e valores de tais agentes. Para essa linha de análise, as redes moldam as ações e as estratégias, mas estas também as constroem e reconstroem continuamente, em um processo dinâmico e contínuo. Da mesma forma, redes e identidades se constituem mutuamente de uma forma complexa que apenas começa a ser explorada. (MARQUES, 1999, p. 47).

Em alternativa à abordagem da sociedade civil produzida nos anos 90, Houtzager, Lavalle, e Acharya (2004) propõem a adoção de uma perspectiva que

[...] preocupa-se antes de tudo com a análise histórica e comparativa de atores institucionalmente situados. Sugere que a participação é um resultado contingente, produzido numa teia de relações negociadas entre atores coletivos (organizações civis, Estado e outros) situados em um terreno institucional preexistente que reprime e/ou facilita formas de ação particulares. (HOUTZAGER, LAVALLE e ACHARYA, 2004, p. 8).

Os autores reiteram a necessidade de uma perspectiva de análise que considere a "teia de relações" nas quais os atores encontram-se imersos, pois suas ações só podem ser compreendidas através da análise das interações que estabelecem com outros atores coletivos em um espaço institucional preexistente que delimitam as suas possibilidades.

Lavalle (2011) explicita os constrangimentos institucionais e vocacionais dos atores, enfatizando que

A recíproca constituição entre Estado e sociedade, ou entre instituições políticas e atores societários, ocorre mediante processos que, ao longo do tempo - e no mesmo movimento - vão moldando e vão sendo moldados pelas diferentes instituições políticas existentes. Essa modelagem recíproca opera mediante a ação estratégica de 
atores relevantes, é claro, mas também por mecanismos consolidados graças a e para além dos cálculos políticos desses atores - notadamente constrangimentos vocacionais e institucionais. (LAVALLE, 2011, p. 9).

Para o autor, as possibilidades dos atores no presente vão estar relacionadas a quanto eles conseguiram, no passado, "arquitetar o seu encaixe institucional" e resguardar os seus interesses no futuro. Esta capacidade vai ser tanto maior quanto melhor posicionado estiver o ator nas conjunturas críticas de inovação institucional (LAVALLE, 2011).

Além disso, os atores se encontram sujeitados a vários níveis de constrangimentos que limitam as suas ações, sobretudo daquelas ações que são explicitadas no âmbito público.

Frente à essas ponderações, parece precipitado interpretar as ações dos atores associativos com base em sua adesão a macroprojetos políticos, pois isto significaria superestimar o fator ideológico na explicação da dinâmica associativa adotada pelos atores. Considera-se, nesse sentido, que as mudanças em termos de padrões organizativos e repertórios de ação das organizações sociais respondem, em boa medida, às mudanças nas oportunidades e restrições políticas e de que forma os atores se utilizam delas. Dentre as organizações da área da assistência que investigamos, nem sempre se podem vincular mudanças organizacionais no sentido de uma maior profissionalização e gestão das ações com a adesão a um projeto político neoliberal. Pela análise dos nossos resultados de pesquisa anteriores, observa-se que o processo de conformação deste "modelo gerencial" é muito mais complexo do que parece a primeira vista, pois seus elementos provêm de diferentes fontes (instituições políticas, agências de cooperação internacional, bancos e organismos internacionais, fundações e institutos privados, organizações da sociedade civil, empresas e instituições religiosas) e foram sendo agregados e modificados, paulatinamente, pelos atores através de suas redes de relações (TIRELLI, 2013). Os estudos de caso apontaram que as organizações sociais irão adotar as ferramentas gerenciais de acordo com a sua trajetória institucional e suas percepções acerca das oportunidades e constrangimentos existentes. Nesse sentido, defende-se que a incorporação de ferramentas de planejamento e de gestão não deve ser interpretada automaticamente como adesão a um projeto político neoliberal. A seguir, descreve-se os principais resultados dos casos analisados.

\section{Análises dos casos investigados}

Pode-se afirmar, desde logo, que os casos da Themis e do COL se constituíram enquanto contra-exemplos de processos amplos de "colonização" da sociedade civil pelos 
atores e metodologias do mercado e do Estado, bem como de processos que evidenciariam a "hegemonização" dessas organizações por um macroprojeto político neoliberal. No entanto, esta observação de forma alguma deve obscurecer as diferenças existentes entre as duas organizações, resultantes das suas distintas trajetórias institucionais e das posições que ocupavam no campo da assistência na "conjuntura crítica" que se abriu nos anos de 1990, que as levou a interpretar e aderir a certas oportunidades políticas de forma particular. Apesar do COL e da Themis atuarem, no presente, enquanto executores de projetos e prestadores de serviço vinculados às políticas públicas, isto é interpretado de forma distinta pelos seus membros.

Mesmo participando de um programa que representa a adesão de setores do Estado a um modelo de trabalho social baseado na parceria público-privada e na valorização de processos de gestão, modelo percebido por parte da literatura nas Ciências Sociais como sendo funcional ao projeto político neoliberal, o que se percebeu em ambos os estudos de caso foi que as organizações não sobrepujaram os seus ideais políticos e ideológicos em função da sua sustentabilidade organizacional e financeira. Embora a situação financeira das organizações estudadas seja muito desigual, tendo o COL recursos próprios que garantem a sua sustentabilidade enquanto a Themis depende totalmente de recursos externos para a sua manutenção, este fator não desencadeou uma adesão ativa dos seus integrantes a um projeto político avesso ao seu. Pelo contrário, as narrativas enfatizaram que as organizações têm participado de editais somente na medida em que esses não comprometessem as suas diretrizes políticas, isto é, desde que a sua "missão" fosse resguardada.

Segundo nos descreveu um dos entrevistados do COL, o fato de existir um planejamento construído coletivamente pelos membros da organização auxilia muito no momento da concorrência em editais, pois a organização até pode se adequar em termos de formatação dos projetos e de linguagem, mas não altera a sua forma de atuação em função da possibilidade de financiamento. De acordo com as suas palavras: “Automaticamente, quando vem algum edital, a gente avalia se esse edital tá de acordo com aquilo que nós nos propomos." Ou seja, não há uma modificação nos programas da organização e muito menos, nas suas diretrizes políticas. Ocorre apenas uma adequação formal as exigências de cada edital. O seguinte depoimento ilustra bem essa postura da organização:

O que muda é o formato do edital, mas o nosso processo já tá construído, a gente só precisa encaixar ele nesse formato, a gente não precisa repensar qual é o nosso objetivo geral, específico, quais são as nossas metas, que resultados a gente quer alcançar, não, ele já está todo formatado. 
No mesmo sentido, outro entrevistado que integra a direção do COL, também deixou claro que, embora exista uma necessidade de ampliar a receita da organização, isto não é feito a qualquer custo, ou seja, a busca por recursos não pode suplantar os valores e princípios defendidos pelo COL. Há, claramente, uma tentativa de aproveitar as oportunidades através da adequação a certas exigências dos editais, mas sempre de forma a fortalecer o trabalho na diretriz política já estabelecida pela organização. A esse respeito, ele comenta:

[...] as opções que nós temos, elas são poucas. Quando a gente entrou nessa história dos projetos, "ah, é uma fonte importante de captar recursos, então vamos construir uma dinâmica pra buscar esses recursos que estão aî”. Não a qualquer custo, a gente sempre teve isso muito claro, mas vamos aproveitar. Aí aparecem as dificuldades que nós temos, pelo diferencial do nosso trabalho. Financiar um projeto hoje via Parceria Social ou qualquer outro, muitos financiadores, que seja somente assistencialista, ainda é o que prevalece. A gente consegue pouco financiamento pra projetos que sejam efetivamente críticos e de transformação. Então o que a gente tenta é fazer esse jeitinho nas duas coisas. Nós tentamos, sim, atender algumas exigências que são dadas e outras que nós podemos colocar de fortalecer o nosso trabalho, a nossa diretriz política.

Em relação às ações de responsabilidade social empresarial, a postura adotada permanece a mesma. Nesse sentido, um entrevistado do COL vai afirmar: "A gente aceita a contribuição deles [dos empresários] desde que a gente não tenha que sair do nosso foco, que a gente permaneça tendo as nossas linhas gerais".

Esta questão também apareceu no estudo de caso da Themis, embora de uma maneira menos consensual entre as entrevistadas. Como esta organização foi financiada durante dez anos pela Fundação Ford, parte das suas integrantes não aceita o fato da organização subsistir no presente através da prestação de serviços ao Estado, enquanto outra parte afirma que isto se faz necessário no atual contexto e que não fere os princípios e autonomia da Themis.

Esta postura de defesa da autonomia da organização em relação ao Estado está presente desde a criação da organização, segundo indicam as entrevistas realizadas com os membros das várias gestões da Themis, embora seja possível identificar algumas nuances nas suas ponderações, relacionadas às conjunturas nas quais a organização encontrava-se inserida em cada momento.

A gente acha que houve uma certa privatização da Themis no sentido de não discussão pública
dos rumos e de planejamento, e por outro lado desse estrangulamento pelo Estado, entende, de
ficar na prestação de serviços do Estado. A falta de dinheiro não pode ser somada ao
recolhimento, ao isolamento porque aí tu não tem abertura de contatos e de possibilidade de
ampliação, de sair do problema. Aí tu só fica refém do Estado mesmo.

A trajetória de constituição dessas organizações de defesa de direitos e a sua sustentação institucional por um largo período pelas agências de cooperação sedimentaram, dentre os seus integrantes, uma visão muito crítica em relação ao acesso aos recursos 
públicos. Na citação a seguir, pode-se perceber a posição da Associação Brasileira de Organizações Não Governamentais (ABONG) frente à forma como vem se efetivando o financiamento do Estado às organizações de defesa de direitos no caso brasileiro:

\begin{abstract}
Quando se constata que os recursos públicos federais tendem a ser uma das principais fontes para as organizações de defesa de direitos, é impossível não assinalar o traço de forte vulnerabilidade que esse processo traz, caso não sejam feitas mudanças substantivas nas modalidades de acesso a tais recursos. A duração dos projetos, as restrições aos gastos com pessoal fixo e gastos institucionais gerais, aliados à ênfase na execução de políticas públicas governamentais são, em muitos pontos, incompatíveis não só com os modelos institucionais que temos, mas principalmente com o que compreendemos como sendo organizações sustentáveis em suas dimensões financeiras e política. (ABONG, 2010, p. 78)
\end{abstract}

\title{
4.1 A entrada no Programa Rede Parceria Social
}

Segundo as narrativas dos integrantes de ambas as organizações investigadas, seu ingresso no PRPS foi movido por razões pragmáticas e pontuais. Isto é, não houve a identificação e incorporação dos pressupostos expressos no programa pelas organizações. Esta postura foi bastante evidenciada na pesquisa, pois os entrevistados das duas organizações disseram que até "dialogam" com os financiadores, mas não abrem mão dos seus valores e princípios. Neste sentido é que se pode falar numa "adaptação pragmática" por parte dos atores das organizações sociais, pois elas até participam de certos processos para a obtenção de recursos para as suas organizações, mas reiteram que isto não é feito a qualquer custo. Nas entrevistas ficou muito clara esta postura quando foram relatados casos nos quais as organizações abriram mão de oportunidades de acesso a certos projetos/recursos por considerar que isto comprometeria a sua missão institucional.

Nos casos que investigamos, os integrantes das organizações avaliaram de forma distinta o aspecto da "prestação de serviços" ao Estado. Enquanto no COL isto não era percebido como um problema, desde que estivesse dentro dos princípios da "missão" e da “visão" institucional, na percepção dos integrantes da Themis, se tornar uma ONG "prestadora de serviços ao Estado" significa perder a sua autonomia e o seu poder de intervenção nos confrontos que envolvem a construção da agenda pública. Neste aspecto, em particular, podese ver como as mesmas oportunidades políticas são interpretadas e apropriadas de forma diversa pelos atores associativos, o que contribui para contestar as teses que apontam para um processo homogêneo e generalizado de colonização dos atores da sociedade civil pelo mercado ou de sua hegemonização por um projeto político neoliberal.

Apesar do COL e da Themis atuarem, no presente, enquanto executores de projetos e prestadores de serviço vinculados às políticas públicas, isto é interpretado de forma distinta 
pelos seus membros. No caso do COL, o fato de ter se constituído enquanto uma organização vinculada à Igreja Católica e voltada à prestação de serviços na área da assistência, o que mudou foi a perspectiva que norteia o trabalho social desenvolvido pela organização ao longo de sua trajetória institucional, o qual deixou de ser um trabalho "assistencialista" e "clientelista", conforme as palavras das nossas entrevistadas do COL, para se voltar à promoção e defesa de direitos de segmentos populacionais vulneráveis. Esta mudança se tornou possível, no caso dessa organização, pelo rearranjo institucional ocorrido nos anos 80, que a aproximou de movimentos sociais populares que lutavam pela redemocratização do país e pela ampliação e garantia dos direitos sociais. A partir de então, o COL passou a atuar em conjunto com esses movimentos, cedendo espaços físicos da instituição para suas reuniões e promovendo trabalhos de assessoria que os auxiliasse nos seus processos de mobilização.

O fato de hoje o COL ter várias frentes de trabalho voltadas à prestação de serviços e execução de políticas públicas através de convênios e parcerias com o Estado - em nível municipal, estadual e federal - não é percebido enquanto um problema pelos seus integrantes: primeiro, porque eles compartilham, em grande medida, da linha política desses programas e participam - nos fóruns e conselhos gestores de políticas e nos conselhos de direitos - do trabalho de controle social e implementação dessas políticas. Além disso, eles não se percebem enquanto "reféns do Estado", pois grande parte dos recursos que financiam os seus projetos provém da própria organização e, o que parece ser o mais importante do ponto de vista dos entrevistados, os projetos realizados para o Estado não se opõem às diretrizes políticas estabelecidas pelo COL. As relações do COL com a agência $\mathrm{KNH}$ e com as empresas, tanto privadas quanto públicas, se desenvolvem dentro da mesma perspectiva, ou seja, as doações são bem-vindas desde que não interfiram nas diretrizes políticas defendidas pela organização e nas metodologias de trabalho que estas requerem.

Já a Themis apresenta algumas peculiaridades em relação à prestação de serviços ao Estado. Como uma ONG de defesa dos direitos humanos das mulheres, criada por um grupo de advogadas feministas no início dos anos 1990, a sua identidade esteve pautada, desde o início, pela perspectiva de manter uma postura de autonomia frente ao Estado. Em várias entrevistas apareceu esta questão como sendo primordial para a organização se manter dentro da sua missão, o mesmo não acontecendo quando as entrevistadas se referiam ao aporte financeiro de organismos e agências internacionais ou fundações privadas (Fundo das Nações Unidas para as Mulheres - UNIFEM, Fundação Ford, Fundação McArthur, Fundação AVINA, entre outras). Estes financiadores jamais foram apontados como agentes que pressionaram ou intervieram nas diretrizes políticas da organização. Essa perspectiva, 
evidenciada nas entrevistas, está vinculada ao tipo de aporte financeiro realizado pelas agências de cooperação internacional durante a década de 1980 e parte da década de 1990. Nesse período, o apoio financeiro era direcionado ao projeto institucional das ONGs como um todo e não a projetos pontuais, permitindo que as organizações se constituíssem como atores sociais com relativa independência em relação ao Estado e ao mercado. ${ }^{10}$ Essa marca na constituição de certas ONGs pode ser percebida nas entrevistas que realizamos com as integrantes da Themis, na medida em que elas reforçam uma visão normativa de sociedade civil, a qual deve ser autônoma em relação ao mercado e ao Estado e virtuosa no que se refere a seus princípios e objetivos.

Na medida em que a Fundação Ford deixou de financiar a Themis em 2004, após dez anos de apoio institucional, a organização necessitou diversificar rapidamente as suas fontes de financiamento para manter-se em atividade. No entanto, todos os relatos de membros das diferentes gestões da Themis, sobretudo daqueles que vivenciaram a "saída da Ford", apontam para a dificuldade em manter uma organização através da execução de projetos específicos, cujos financiamentos, de uma forma geral, não permitem o custeio da própria organização (pagamentos de luz, água, telefone, internet, salários, tributos).

A necessidade de obtenção de recursos financeiros, por parte da Themis, levou a organização a executar vários projetos vinculados aos programas governamentais, tanto em nível federal quanto estadual e municipal. No entanto, segundo os relatos das entrevistadas, como esses projetos, em geral, não permitem o pagamento de despesas relacionadas à manutenção das organizações, eles acabam levando-as a um processo de "estrangulamento" financeiro, pois as organizações vão acumulando dívidas de difícil resolução.

Este processo de contratação das organizações da sociedade civil pelo Estado acaba aproximando as ONGs de defesa de direitos de outras organizações/entidades que atuam no campo da assistência também prestando serviços ao Estado. No entanto, a avaliação dos membros dessas organizações em relação a esse tipo de trabalho é bastante distinta como se pôde perceber no caso de nossa pesquisa, pois as ONGs de direitos se constituíram sobre outra lógica e consideram esse processo como algo a ser evitado e confrontado pelas organizações. Frente a isso, seus membros defendem a criação de um marco regulatório que permita a formação de fundos públicos para financiar as ONGs sem a instrumentalização do formato operado no presente pelo Estado.

\footnotetext{
${ }^{10}$ Na publicação da ABONG (2010) há uma referência a essa parcela de ONGs brasileiras que receberam, por um período relativamente longo, o apoio das agências de cooperação internacional a seus projetos institucionais, fator que vai repercutir na formação de suas identidades e nas construções futuras de suas alternativas de sustentabilidade.
} 


\title{
Considerações finais
}

Como se pode perceber, as organizações se relacionam de maneira muito particular com um mesmo programa da Área da Assistência.

Nos casos investigados parece ocorrer uma espécie de "adaptação pragmática" dos objetivos e princípios do Programa (SCOTT, 1990) por parte das organizações, ou seja, elas elaboram algumas alterações em seu trabalho sem que isto signifique uma adesão ativa aos valores de quem as financia, o que possibilita estabelecer diálogos com os financiadores e adequar a linguagem dos projetos de acordo com as exigências dos editais, desde que isso não interfira na manutenção dos seus ideais mais caros. No entanto, apesar de se identificar essa mesma postura nas duas organizações estudadas, o temor que seus integrantes expressam se referem a processos distintos, constituídos ao longo de suas trajetórias organizacionais. No caso da Themis, por exemplo, aparece claramente o receio de que a organização perca a sua a autonomia política, na medida em que passe a ser contratada pelo Estado para a implementação de políticas públicas, ou seja, se transforme em uma ONG "prestadora de serviços ao Estado”. Já nas entrevistas feitas com membros do COL aparece de forma mais enfática a idéia de que as organizações civis não devem substituir o Estado nas suas atribuições constitucionais, o que não impede a realização de um trabalho complementar ao do Estado e com o aporte de recursos públicos.

Concluindo, pode-se dizer que as organizações ingressaram no PRPS com fins muito pragmáticos e pontuais, ou seja, isto não significou uma incorporação dos seus pressupostos ideológicos. Pôde-se perceber, também, que cada organização possui uma trajetória institucional que se traduz em possibilidades diferenciadas de apropriação do modelo que o Programa advoga, o que reforça a importância de se considerar a contingência que envolve as ações dos atores, sempre condicionadas por um campo relacional e pela posição que ocupam neste campo.

\section{FROM COLONIZATION TO THE DOING OF ACTORS: THE IMPLEMENTATION OF PUBLIC POLICY BY CIVIL ORGANIZATIONS}

\author{
Abstract \\ The article discusses the different appropriations of a public policy - Programa Rede Parceria \\ Social - through the civil organizations that act in the field of Social Assistance in Rio Grande \\ Do Sul, by two case studies made in 2011 and 2012. Through a theoretical framework based
}


on relational sociology and historical institutionalism, it is evaluated how the institutional trajectory of social actors, which led them to currently occupy certain (relational) positions in the field of Assistance, conditions their way to interpret and take appropriation of political opportunities as the one represented by the Programa Rede Parceria Social. In this sense, it is put under suspicion the thesis presented by Brazilian Social Sciences that lead to generalized processes of "colonization" of civil society by the market and or its "hegemonization" through a neoliberal political project. In this article, we start from the premise that the way through which the organizations will relate with political opportunities, in a certain scenario, is something to be verified by empirical investigations and, thus, cannot be answered through causal inferences that respond a priori about the intentions of the agents and the results of their actions.

Keywords: Rede Parceria Social. Social Assistance. Relational Sociology. Historical Institutionalism.

\section{DE LA COLONIZACIÓN A LA AGENCIA DE LOS ACTORES: LA IMPLEMENTACIÓN DE POLÍTICAS PÚBLICAS POR LAS ORGANIZACIONES CIVILES}

\section{Resumen}

El artículo aborda las diferentes apropriaciones de una política pública - Programa Rede Parceria Social - por las organizaciones sociales que operan en el campo de la Asistencia Social en Río Grande do Sul, a través de dos estudios de caso en los años 2011 y 2012. Desde una perspectiva teórica de la sociologia relacional y el institucionalismo histórico, examina cómo la trayectoria institucional de los actores sociales, que los llevó a ocupar ciertas posiciones (relacionales) en el campo de la asistencia, ha condicionado la forma como tales organizaciones interpretan y se apropian de las oportunidades políticas como la representada por el Programa Rede Parceria Social. Por consiguiente, quedan bajo sospecha las tesis proferidas por las ciencias sociales brasileñas que apuntan a procesos generalizados de "colonización" de organizaciones de la sociedad civil por el mercado o de su "hegemonización" por um proyecto político neoliberal. En este artículo partimos de la premisa que el camino por el cual las organizaciones se relacionan con las oportunidades políticas, en particular, es algo a ser verificado a través de investigaciones empíricas y, por lo tanto, no pueden ser contestadas a través de inferencias causales que responden a priori sobre la intencionalidad de los agentes y sobre los resultados de sus acciones.

Palabras clave: Rede Parceria Social. Asistencia social. Sociología relacional. Institucionalismo histórico

\section{Referências}

ABERS, Rebecca e VON BÜLLOW, Marisa. Movimentos sociais na teoria e na prática: como estudar o ativismo através da fronteira entre Estado e sociedade? Revista Sociologias, Porto Alegre, ano 13, n.28, set./dez. 2011, p.52-84. 
ABONG. Sustentabilidade das ONGs no Brasil: acesso a recursos privados. Rio de Janeiro: ABONG, 2010. 92p.

ALMEIDA, Carla. O marco discursivo da "Participação Solidária" e a nova agenda de formulação e implementação de ações sociais no Brasil. In: DAGNINO, E., OLVERA, A. e PANFICHI, A.(Orgs.). A disputa pela construção democrática na América Latina. São Paulo: Paz e Terra; Campinas: Unicamp, 2006, p. 95-135.

CAPOCCIA, Giovanni e KELEMEN, R. Daniel. The Study of Critical Junctures: theory, narrative, and counterfactuals in historical Institutionalism. World Politics, 59, p. 341-369, April/2007.

COUTINHO, Joana Aparecida. ONGs e Políticas Neoliberais no Brasil. Florianópolis: UFSC, 2011.

DAGNINO, Evelina. Sociedade civil, espaços públicos e a construção democrática no Brasil: limites e possibilidades. In: DAGNINO, Evelina (Org.). Sociedade civil e espaços públicos no Brasil. São Paulo: Paz e Terra, 2002, p. 279-301.

DAGNINO, E., OLVERA, A. e PANFICHI, A. Para uma outra leitura da disputa pela construção democrática na América Latina. In: DAGNINO, E., OLVERA, A. e PANFICHI, A. (Orgs.). A disputa pela construção democrática na América Latina. São Paulo: Paz e Terra; Campinas: Unicamp, 2006, p.13-91.

DOWBOR, Mônika. Sujeitos da assistência social. Estado, entidades assistenciais, assistentes sociais e usuários na trajetória da assistência social entre 1974 e 2005. In: CONGRESSO BRASILEIRO DE SOCIOLOGIA, 14, 2009a, Rio de Janeiro. Anais eletrônicos. Rio de Janeiro: SBS, 2009a. Laboratório de Pesquisa. Disponível em: <http://www.sbs2009.sbsociologia.com.br>. Acesso em: 8 de out. de 2010.

HOUTZAGER, Peter P., Gurza LAVALlE, Adrián e ACHARYA Amab. Atores da sociedade civil e atores políticos - participação nas novas políticas democráticas em São Paulo. In: Avritzer, Leonardo (Org.). A participação em São Paulo. São Paulo: UNESP, 2004.

IBGE, IPEA, GIFE e ABONG. As Fundações Privadas e Associações sem Fins Lucrativos no Brasil 2010. Rio de Janeiro: IBGE, 2012.

JAIME, Pedro. O empresariado e a questão social: apontamentos para a interpretação de um novo associativismo empresarial no Brasil. Revista de Administração Pública, Rio de Janeiro, v. 39, n. 4, p. 939-78, jul./ago., 2005.

LAVALLE, A. G. O estatuto político da sociedade civil: evidências da cidade do México e de São Paulo. Brasília, DF: CEPAL. Escritório no Brasil/IPEA. Textos para discussão CEPALIPEA, $\quad$ n. 28, 2011. Disponível em: $<$ http://www.cepal.org/brasil/publicaciones/sinsigla/xml/2/43432/CEPAL_28.pdf>. Acesso em: 14 de junho de 2012.

LAVALLE, Adrián Gurza; HOUTZAGER, Peter P.; CASTELLO, Graziela. Democracia, pluralização da democracia e sociedade civil. Lua Nova, São Paulo, 67: 49-103, 2006. 
MARQUES, Eduardo César. Redes sociais e instituições na construção do Estado e da sua permeabilidade. Revista Brasileira de Ciências Sociais, v.14, n.41, outubro de 1999, p. 45-67.

MARTINS, Gilberto. A. Estudo de caso: uma reflexão sobre a aplicabilidade em pesquisas no Brasil. Revista de Contabilidade e Organizações, v. 2, n. 2, p. 9-18, jan./abr. 2008.

MESTRINER, Maria Luiza. O Estado entre a filantropia e a assistência social. São Paulo: Cortez, 2001.

MONTAÑO, Carlos. Terceiro Setor e questão social: crítica ao padrão emergente de intervenção social. São Paulo: Cortez, 2002.

MÜLLER, Lúcia. A construção do social a partir da ótica empresarial. In: WORKSHOP EMPRESA, EMPRESÀRIOS E SOCIEDADE, 5, Porto Alegre: PUCRS, 2006. 1 CD-ROM.

PAOLI, Maria Célia. Empresas e responsabilidade social: os enredamentos da cidadania no Brasil. In: SANTOS, Boaventura Sousa (org.). Democratizar a democracia: caminhos da democracia participativa. Rio de Janeiro: Civilização Brasileira, 2002.

PAULA, Sérgio Goes e ROHDEN, Fabíola. Filantropia empresarial em discussão: números e concepções a partir do estudo do Prêmio Eco. In: LANDIM, Leilah (Org.). Ações em sociedade: militância, caridade, assistência etc. Rio de Janeiro: NAU, 1998.

REVISTA REDE PARCERIAS SOCIAIS. Porto Alegre: Secretaria da Justiça e do Desenvolvimento Social do RS, julho de 2009.

SCOTT, James C. Domination and the Arts of Resistance: Hidden Transcripts. New Haven, Yale University, 1990.

SILVA, Marcelo Kunrath da. Sociedade civil e construção democrática: do maniqueísmo essencialista à abordagem relacional. Sociologias, Porto Alegre, ano 8, n. 16, p.156-178, jul./dez. 2006.

SOARES, Erika Scheeren. O paralelismo da Rede Parceria Social do RS com a Política Nacional de Assistência Social. 247f. Tese (Doutorado em Serviço Social) - Faculdade de Serviço Social, Pontifícia Universidade Católica do Rio Grande do Sul, Porto Alegre, 2012.

SORJ, Bernardo. Sociedades Civis e Relações Norte-Sul: Ongs e Dependência. Rio de Janeiro: Centro Edelstein de Pesquisas Sociais, 2005.

TATAGIBA, Luciana. Os desafios da articulação entre Sociedade Civil e Sociedade Política sob o marco da democracia gerencial. O caso do Projeto Rede Criança em Vitória/ES. In: DAGNINO, E., OLVERA, A. e PANFICHI, A. (Orgs.). A disputa pela construção democrática na América Latina. São Paulo: Paz e Terra; Campinas: Unicamp, 2006, p. 137178.

TIRELLI, Cláudia. Reconfiguração da Assistência e Organizações Sociais no RS: um estudo das organizações que participaram do Programa Rede Parceria Social entre 2008 e 2010. Tese (Doutorado). Universidade Federal do Rio Grande do Sul, Instituto de Filosofia e Ciências Humanas, Programa de Pós-Graduação em Sociologia, Porto Alegre, 2013. Disponível em: 
http://www.lume.ufrgs.br/bitstream/handle/10183/81364/000902144.pdf

YASBEK, Maria Carmelita. Os fundamentos históricos e teórico-metodológicos do Serviço Social brasileiro na contemporaneidade, In: Serviço social: direitos sociais e competências profissionais. Natal: CFESS. 2009, p.1-27.

YIN, Robert K. Estudo de caso: planejamento e métodos. Porto Alegre: Bookman, 2001.

Data de recebimento: 29/10/15

Data de aceite: $29 / 07 / 16$

\section{Sobre a autora}

Cláudia Tirelli é doutora em Sociologia pela Universidade Federal do Rio Grande do Sul. Professora do Departamento de Ciências Humanas e do Programa de Pós-Graduação em Desenvolvimento Regional da Universidade de Santa Cruz do Sul e Coordenadora do Núcleo de Pesquisa Social desta Universidade. Endereço eletrônico: ctirelli@ unisc.br . 